\title{
WLB in Zahlen 2012
}

\begin{tabular}{|c|c|}
\hline \multicolumn{2}{|l|}{ Gesamtbestand (Stand: 4.3.2013) } \\
\hline Medienbestand insgesamt & 5.795 .614 \\
\hline \multicolumn{2}{|l|}{ davon: } \\
\hline Buchmaterialien & 3.808 .101 \\
\hline Autographen & 180.460 \\
\hline Handschriften & 15.461 \\
\hline Inkunabeln & 7.087 \\
\hline Noten & 70.495 \\
\hline Karten & 152.603 \\
\hline Mikroformen & 473.114 \\
\hline AV-Materialien (Ton-, Bildträger) & 43.709 \\
\hline CD-ROMS & 22.775 \\
\hline Flugblätter & 159.853 \\
\hline Fotos & 579.294 \\
\hline Plakate & 39.800 \\
\hline Feldpostbriefe & 127.715 \\
\hline Porträts & 36.901 \\
\hline $\begin{array}{l}\text { davon: Varia 3.375, Disketten 3.391, Ortsansichten 8.278, Ansichtskarten 36.010, Ereignisdarstellungen 2.000, } \\
\text { Sonstiges Sig. Nicolai 22.000, Einblattmat./Sonstige 3.035, Nachlässe 157 }\end{array}$ & 78.246 \\
\hline Bibeln (in 644 Sprachen) & 19.630 \\
\hline Zeitschriften u. Zeitungen (Abos) & 12.068 \\
\hline Angebot an elektronischen Zeitschriften & 22.270 \\
\hline Angebot an online-Datenbanken & 265 \\
\hline Angebot an E-Books & 15.741 \\
\hline Zugang 2012 & 57.811 \\
\hline Kauf & 23.506 \\
\hline Pflicht & 27.225 \\
\hline Tausch & 554 \\
\hline Geschenk & 6.526 \\
\hline \multicolumn{2}{|l|}{ Benutzung 2012} \\
\hline Öffnungstage & 292 \\
\hline Öffnungsstunden pro Woche & 64 \\
\hline Entleihungen insgesamt & 1.271 .987 \\
\hline Aktive Benutzer/innen & 31.511 \\
\hline Benutzerfälle in den Lesesälen & 268.089 \\
\hline Benutzerschulungen / Führungen (Stunden) & 388 \\
\hline Fernleihbestellungen (aktiv, pos. erledigt) & 38.325 \\
\hline Fernleihbestellungen (passiv, pos. erledigt) & 20.731 \\
\hline Direktlieferdienste & 27.714 \\
\hline Personalstellen 2012 & 129 \\
\hline Kulturelle Veranstaltungen 2012 & 30 \\
\hline Ausstellungen & 10 \\
\hline Weitere Veranstaltungen & 20 \\
\hline
\end{tabular}

